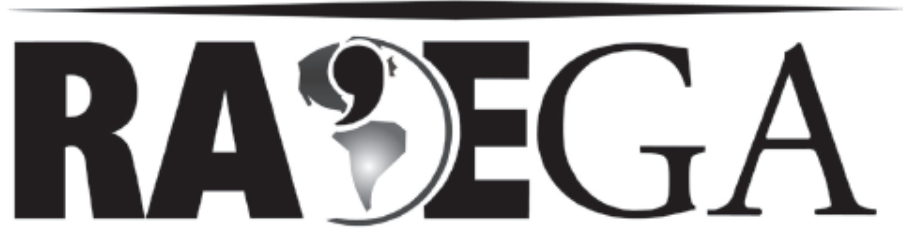

O ESPAÇO GEOGRÁFICO EM ANÁLISE

\title{
AS PAISAGENS DA MEMÓRIA E A IDENTIDADE RELIGIOSA
}

\section{THE MEMORY LANDSCAPES AND THE RELIGIOUS IDENTITY}

\author{
Marcos Alberto Torres ${ }^{1}$
}

\section{RESUMO}

As relações entre percepção e memória na construção da identidade religiosa são debatidas no presente trabalho, com vistas a apresentar elementos que contribuam à compreensão das paisagens da memória e de sua relação com a espacialidade religiosa. Tendo como base o pensamento de Ernst Cassirer, para o qual o ser humano é dotado de uma capacidade de imaginação e inteligência simbólica, procura-se contribuir aos estudos geográficos de modo a apresentar um conceito de paisagem que não se limita à materialidade das formas visíveis e que, da mesma forma, possa subsidiar os estudos acerca da espacialidade do sagrado.

Palavras-chave: percepção; memória; paisagem; identidade religiosa; espacialidade religiosa.

\section{ABSTRACT}

The relationship between perception and memory in the construction of religious identity are discussed in this paper, in order to introduce elements that contribute to the understanding of the landscapes of memory and its relation to

\footnotetext{
${ }^{1}$ Mestre e Doutorando do Programa de Pós-Graduação em Geografia da Universidade Federal do Paraná - UFPR, Professor Assistente Substituto do Setor de Educação da UFPR. Curitiba, Paraná, Brasil. torresmarcos@hotmail.com
} 
religious spatiality. Based on the thought of Ernst Cassirer, for which the human being is endowed with a capacity of symbolic imagination and symbolic intelligence, seeks to contribute to geographic studies in order to present a concept of landscape which is not limited to the materiality of visible forms and, similarly, can subsidize the studies of the spatiality of the sacred.

Keywords: perception; memory; landscape; religious identity; religious spatiality.

\section{INTRODUÇÃO}

A interação do ser humano com o espaço faz da paisagem algo em constante transformação, seja no plano da materialidade das coisas que os seres humanos constroem/desconstroem e organizam no espaço, seja no plano da imaterialidade, dos sentidos e significados atribuídos a cada elemento constituinte da paisagem. A paisagem, portanto, está carregada de elementos simbólicos, que se baseiam na experiência e leitura de mundo de cada indivíduo que com ela interage.

O ser religioso, dotado de experiências com o sagrado, é capaz de valorar os elementos sagrados e profanos que se manifestam na paisagem. Contudo, tais valores dependem de suas experiências e de suas convicções religiosas. As experiências contribuem para a construção e/ou reafirmação da identidade religiosa, englobando nesse processo percepções e memórias de cada indivíduo e do grupo.

O presente trabalho tece relações entre a percepção e a memória na construção da identidade religiosa, que implica na espacialidade religiosa por meio do espaço de ação do ser religioso. Para tanto, primeiramente trará contribuições ao conceito de paisagem à Geografia, em um diálogo entre a ideia de paisagem cultural e o pensamento de Ernst Cassirer acerca da cultura humana, para em seguida discorrer sobre a percepção e a memória na construção de paisagens da memória e da participação destas na construção da identidade religiosa. Dessa forma, são apresentados elementos que ajudam a explicar a espacialidade do sagrado, uma vez que esta se dá nos diferentes espaços pelos quais as pessoas religiosas percorrem em seu cotidiano. 


\section{DA PAISAGEM À PAISAGEM RELIGIOSA}

A paisagem é um complexo de formas e relações culturais, e traz em si valores erigidos no decorrer do tempo. Os valores constroem-se juntamente com o desenvolvimento do ser humano, que interage diretamente com o meio, refazendo-se nele, visto que "a paisagem não pode ser separada do homem, do seu espírito, da sua imaginação e percepção" (ANDREOTTI, 2012, p.06). Para Almeida (2003, p.86), "a paisagem é uma complexidade multiforme de realidades, de valores, de gestos e de vividos coexistentes". Ao mesmo tempo em que a paisagem apresenta elementos da(s) vida(s) que a habita, é refletida por cada vida que nela há. A paisagem contempla a manifestação material - 0 espaço objetivo - base da construção do universo simbólico ${ }^{2}$, pois é a partir do que se percebe da paisagem que o ser humano representa o mundo e a si mesmo.
À medida que a percepção não se mantém como mera apreensão de algo isolado, de algo dado aqui e agora, à medida que ela conquista o caráter da "representação", ela agrupa uma variada abundância de fenômenos em um "contexto da experiência". A separação entre os dois fatores básicos da representação - entre representante e representado - traz em si o germe a partir do qual o mundo do espaço desenvolve-se plenamente como um mundo da intuição pura. (CASSIRER, 2011, p.274)

Nesse sentido, a paisagem contempla, além dos elementos materiais, os imateriais, frutos da relação do homem com o meio, produtora de sentidos e significados. De acordo com Andreotti (2008), homem e paisagem estão em diálogo constante, pois a cultura reflete na - e é reflexo da - paisagem. Para a autora existe uma distinção entre a paisagem geográfica ou humanizada e a paisagem cultural. A primeira, para ela, é uma paisagem genérica, que depende apenas da interpretação do homem. Quanto à segunda, ela define da seguinte forma:

\footnotetext{
2 Para Ernst Cassirer (1994), o ser humano é portador de um sistema simbólico, representado pela capacidade de imaginação e inteligências simbólicas. Dessa forma, o homem vive em um universo simbólico, sendo que o mito, a arte, a religião e a linguagem são partes desse universo, do qual o ser humano articula para dar sentido à vida e às coisas.
} 


\begin{abstract}
A paisagem cultural é, por sua vez, rara: contém alma. Por isso o passado não é mais passado porque, por via da integração psicológica, é sempre uma relação com o observador. Portanto, deve ser pensado - e esta é uma das inumeráveis possibilidades de interpretação - como um fato íntimo, espiritual, psicológico ${ }^{3}$. (ANDREOTTI, 2008, p.24)
\end{abstract}

Ao desenvolver o conceito de paisagem cultural, Andreotti aponta para a necessidade da utilização da dimensão psicológica para tal conceito. Pensar a paisagem implica, antes de tudo, pensar no indivíduo que nela está, dando significado a ela, construindo-a ou mesmo alterando-a. Nesse sentido, a paisagem pode ser considerada também como unidade de apreensão de uma determinada porção do espaço, e sua descrição e análise estão carregadas dos significados que são atribuídos pelo seu observador, construídos ao longo do tempo.

Andreotti (2012, p.07) afirma que "a paisagem exprime o homem, mas ao mesmo tempo faz o homem". No mesmo sentido, Cosgrove (2004, p.108) destaca que "todas as paisagens possuem significados simbólicos porque são o produto da apropriação e transformação do meio ambiente pelo homem". Numa escala de análise que englobe a coletividade, pode-se afirmar que cada cultura, segundo seus valores, apropria-se dos elementos do meio e transforma-os, o que é expresso na paisagem.

Sendo a paisagem uma unidade do espaço que possui relação direta com o ser humano e com a cultura, por refleti-los e por eles ser refletida numa relação em constante transformação, - torna-se pertinente que, no estudo da paisagem, busque-se compreender as percepções e memórias dos indivíduos que estão integrados a ela.

As paisagens, ao conformarem-se no subjetivo de cada indivíduo, constroem-se, sobretudo, a partir de suas experiências também com a coletividade, e que, ao encontrar similitudes nos demais indivíduos do grupo que se tornam elos de contato -, conferem identidade ao indivíduo e ao grupo. Nessa relação de três pilares, que envolve o indivíduo, o coletivo e a paisagem,

\footnotetext{
${ }^{3}$ Tradução livre da versão italiana. No original: Il paesaggio culturale è, invece, raro: ha un'anima. Per esso il passato non è mai passato perché, per via dell'integrazione psicologica, è sempre in rapporto con l'osservatore. Dunque, deve essere pensato - e questa è un'altra delle innumerevoli possibili interpretazioni - come un fatto intimo, spirituale, psicologico.
} 
está também em constante construção uma história, portadora de um discurso (figura 01).

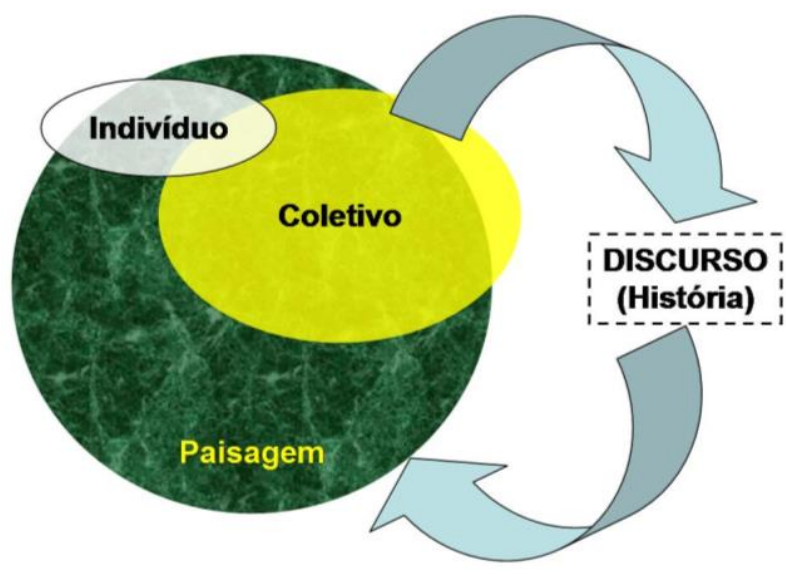

Figura 01 - Componentes da paisagem Organização: Marcos Torres, 2012.

Assim, a paisagem, além de conter o indivíduo, contém também as histórias e os discursos, tanto do indivíduo quanto da coletividade. Expressa, dessa maneira, as memórias individuais e coletivas, os valores construídos ao longo do tempo, e, principalmente, a comunicação dessas memórias e valores. Os discursos decorrentes da paisagem e presentes nela podem estar contidos em uma ou mais formas simbólicas (arte, mito, religião, linguagem), o que garante o sentido atribuído a cada paisagem. Portanto, numa observação estética da paisagem que considere apenas os subsídios materiais visíveis, elementos do sagrado podem passar despercebidos, o que inviabiliza ou minimiza o potencial do estudo da paisagem religiosa. Assim, a paisagem deve ser estudada em seus diferentes aspectos sensíveis (formas, cheiros, sons, texturas, cores, sabores, movimentos), pois é a partir deles que os indivíduos percebem-na e atribuem significados a cada elemento que a constitui.

Os templos religiosos costumeiramente apresentam-se como marcos na paisagem, com edificações características. Contudo, no interior de cada um deles, há uma paisagem específica, religiosa, que contém elementos que remetem ao sagrado. Cada espaço religioso apresenta-se como lugar familiar às pessoas que o frequentam e que nele experimentam as manifestações do sagrado, além de compartilharem entre si a fé e suas conviç̧ões, que se manifestam na paisagem, e integram o cotidiano do ser religioso. Assim, a 
paisagem religiosa contempla as manifestações do sagrado, e por conter elementos que podem sugerir ao ser religioso o contato com o sagrado, contribui para reforçar e/ou reafirmar sua identidade, bem como a identidade do grupo. As percepções e as memórias vivenciadas, construídas e compartilhadas no seio do grupo de religiosos, apresentam-se como importantes elementos à compreensão da espacialidade religiosa.

\section{PERCEPÇÃO E MEMÓRIA}

As representações acerca dos lugares podem se dar de maneira distinta entre os seres humanos, pois estes se baseiam, sobretudo, em suas experiências e vivências, que estão no plano da percepção e integram suas memórias. A memória é uma faculdade decorrente de uma organização neurobiológica complexa, da qual todo ser humano é dotado, salvo os casos patológicos. Remete à capacidade de recordar experiências outrora vivenciadas, e pode ser desencadeada através da interação social, ou do contato com objetos ou situações que remetam a tais experiências. Quando compartilhada dentro de um grupo, a memória pode contribuir para a construção ou fortalecimento de uma identidade pessoal e/ou coletiva. Para Halbwachs (2006), há uma relação direta entre a memória individual e a memória coletiva, o que faz das memórias uma característica sempre presente na vida humana. Segundo ele,

Para que a nossa memória se aproveite da memória dos outros, não basta que estes nos apresentem seus testemunhos: também é preciso que ela não tenha deixado de concordar com as memórias deles e que existam muitos pontos de contato entre uma e outras para que a lembrança que nos fazem recordar venha a ser reconstruída sobre uma base comum. (HALBWACHS, 2006, p.39)

A memória é um fenômeno individual, mas que, conforme explicita Halbwachs, perpetua-se e reconstrói-se na coletividade. Nesse processo, porém, a linguagem atua com fundamental importância, reproduzindo imagens representacionais que remetem aos fatos vividos por cada pessoa.

Para Bergson (2006), a percepção e a lembrança se interpenetram 
constantemente, o que evidencia a relação direta estabelecida entre a percepção e a memória. Para este autor,

Se a percepção exterior, com efeito, provoca de nossa parte movimentos que a desenham em linhas gerais, nossa memória dirige à percepção recebida as antigas imagens que se assemelham a ela e cujo esboço já foi traçado por nossos movimentos. Ela cria assim pela segunda vez a percepção presente, ou melhor, duplica essa percepção ao lhe devolver, seja sua própria imagem, seja uma imagem-lembrança do mesmo tipo. Se a imagem retida ou rememorada não chega a cobrir todos os detalhes da imagem percebida, um apelo é lançado às regiões mais profundas e afastadas da memória, até que outros detalhes conhecidos venham a se projetar sobre aqueles que se ignoram. E a operação pode prosseguir indefinidamente, a memória fortalecendo e enriquecendo a percepção, a qual, por sua vez, atrai para si um número crescente de lembranças complementares. (BERGSON, 2006, p.114-115)

Seguindo esse raciocínio, Bergson propõe um esquema a partir de círculos justapostos, para representar os níveis de expansão da memória e os níveis de profundidade espaço-temporal dos objetos evocados, esquema que se fundamenta na relação percepção-memória (figura 02).

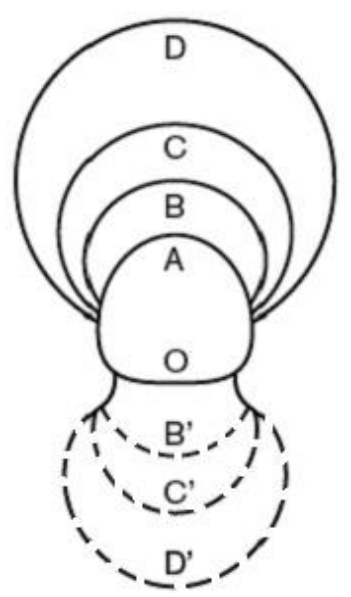

Figura 02 - Círculos da memória Fonte: BERGSON, 2006, p.118.

O que o esquema procura ilustrar é que a memória pode ser representada a partir de círculos, sendo o mais restrito o $A$, este mais próximo da percepção imediata, que contém apenas o próprio objeto $O$. Os círculos que seguem, $B, C$, e $D$, cada vez maiores, respondem a esforços da expansão intelectual. É a totalidade da memória, que entra em cada um desses circuitos, 
uma vez que a memória está sempre presente. Mas essa memória reflete sobre o objeto um número crescente de coisas sugeridas, ora detalhes do próprio objeto, ora detalhes concomitantes que ajudam a esclarecê-lo. Após ter reconstruído o objeto percebido, como um todo independente, reconstituímos com ele as condições cada vez mais longínquas com as quais forma um sistema. Assim, denomina-se $B^{\prime}, C^{\prime}$, e $D^{\prime}$ as causas de profundidade crescente, situadas atrás do objeto, e virtualmente dadas com o próprio objeto. O que se vê da atenção tem por efeito criar de novo, não apenas o objeto percebido, mas os sistemas cada vez mais vastos aos quais ele pode se associar. Assim, à medida que os círculos $B, C$, e $D$ representam a expansão crescente da memória, sua reflexão atinge em $B^{\prime}, C^{\prime}$, e $D^{\prime}$ camadas mais profundas da realidade (BERGSON, 2006, p.119-120). O dinamismo interno da memória, ao partir de uma imagem qualquer, é capaz de gerar outras imagens por meio de associações. Assim, o esquema proposto vai além de apresentar as relações existentes entre a percepção e a memória, mas demonstra a complexidade que se dá nos processos da memória.

Bosi (1994), porém, destaca que ao centrar-se na subjetividade do sujeito da memória, falta no pensamento de Bergson "um tratamento da memória como fenômeno social" (p.54), o que, nesse sentido, Halbwachs vem preencher essa lacuna ao interrelacionar a memória da pessoa à memória do grupo. Ao destacar o pensamento de Halbwachs, Bosi acrescenta que "a memória do indivíduo depende do seu relacionamento com a família, com a classe social, com a escola, com a Igreja, com a profissão; enfim, com os grupos de convívio e os grupos de referência peculiares a esse indivíduo" (BOSI, 1994, p.54).

Portanto, a memória possui estreita relação com a percepção, e apresenta-se também como um fenômeno social. Destarte, entende-se que as memórias não são apenas vividas na individualidade, mas compartilhadas entre as pessoas de um ou mais grupos. A comunicação acerca da memória, deste modo, ocorrerá por meio da linguagem, o que também concede à memória uma característica simbólica.

Para Cassirer (1994), o processo pelo qual o homem não só repete sua 
experiência passada, mas também reconstrói essa experiência, é denominado memória simbólica, sendo que "a imaginação torna-se um elemento necessário da verdadeira lembrança" (CASSIRER, 1994, p.89). Para Almeida, a "imaginação é a faculdade de evocar imagens ausentes, fictícias, irreais, enterradas no nosso mais profundo eu" (ALMEIDA, 2003, p.73). Portanto, no processo que envolve a percepção e a memória, está presente a imaginação, o que torna essencial a linguagem para a comunicação das imagens que resultam desse processo.

Jöel Candau (2011, p.21-23) propõe uma classificação da memória a partir de três categorias distintas, que são:

1. Protomemória ou memória de baixo nível, que engloba as técnicas do corpo, memórias gestuais, rotinas, traços, marcas e condicionamentos constitutivos do ethos, dentre outros;

2. A memória propriamente dita ou de alto nível, que é essencialmente uma memória da recordação ou reconhecimento;

3. A metamemória, que é tanto a representação que cada indivíduo faz de sua própria memória, o conhecimento que tem dela, como o que diz dela. Está ligada à construção explícita da identidade. Para o autor, é uma memória reivindicada, ostensiva.

Segundo Candau (2011, p.23), a protomemória e a memória de alto nível dependem diretamente da faculdade da memória, enquanto a metamemória é uma representação relativa a essa faculdade. Como exemplos, andar de bicicleta sem cair ou saudar gestualmente uma pessoa que anda na rua, são capacidades que se valem da protomemória. Já a capacidade de mobilizar várias lembranças, recentes ou antigas, é uma forma de memória de alto nível. Por fim, cada ser humano tem uma ideia de sua própria memória e é capaz de discorrer sobre ela para destacar suas particularidades, seu interesse, sua profundidade ou suas lacunas: aqui se trata da metamemória (CANDAU, 2011, p.24).

A classificação proposta por Candau equivale apenas no plano do indivíduo, ao que o mesmo autor chama a atenção, uma vez que apenas a noção de metamemória ou de memória evocativa pode ser pretendida no 
grupo. Entretanto, entende-se que as pessoas de um mesmo grupo não recordem de maneira idêntica, pois a memória, como vimos em Bergson, está em estrita relação com a percepção. A memória coletiva, portanto, é "uma representação, uma forma de metamemória, quer dizer, um enunciado que membros de um grupo vão produzir a respeito de uma memória supostamente comum a todos os membros desse grupo" (CANDAU, 2011, p.24). Assim, os indivíduos percebem e representam os fatos e os lugares de maneiras distintas, uma vez que se baseiam em suas experiências e vivências, construídas, armazenadas e (re)significadas em suas memórias (TORRES, 2009, p.28). O compartilhamento das memórias individuais e coletivas, e, conseqüentemente, a construção das memórias coletivas, contribuem para a construção das identidades.

\section{A CONSTRUÇÃO DAS IDENTIDADES E A ESPACIALIDADE RELIGIOSA}

Segundo Lowenthal (1998), a recordação do passado é crucial para nosso sentido de identidade, pois saber o que éramos confirma o que somos. Candau (2011, p.25), por sua vez, ao refletir sobre o conceito de identidade, indica que quando aplicado para referir-se ao indivíduo, a identidade pode ser um estado, resultante, por exemplo, de uma instância administrativa, e para isso ele usa o exemplo do documento de identidade, que conduz à ideia de representação. $O$ autor apresenta críticas à aplicação do termo identidade a um grupo, o que para ele é impróprio, pois nunca é possível designar com rigor uma recorrência. Desse modo, Candau pontua que o termo utilizado para um grupo é menos restrito, próximo ao de semelhança ou similitude. Assim, para ele, a admissão do uso do termo identidade com pouco rigor conduzirá a uma identidade, cultural ou coletiva, como representação. A crítica do autor está, sobretudo, na "confusão" que pode surgir entre a metamemória e a memória coletiva, resultando na ilusão de uma memória compartilhada. Contudo, ao compreendermos que o papel da língua na comunicação das memórias é traduzi-las numa determinada direção da apreensão e visão, conforme alerta Cassirer (2001), fica evidente que toda metamemória contém sua própria representação, e sua comunicação gerará uma certa "ilusão" de 
compartilhamento, pois o indivíduo que recebe a informação acerca da memória do outro ou da coletividade, buscará em suas vivências pontos de contato para a compreensão da memória que diz respeito à coletividade, e a partir disso a tratará como sendo também sua.

$\mathrm{Na}$ religião, a identidade possui dupla conotação, que é a identidade institucional e a individual (sentimento de pertença), e entre elas há uma interdependência, uma vez que o sentimento de pertença remete à instituição. Para o ser religioso, o convívio com a comunidade religiosa permite a experiência com o sagrado, a troca de informações, a manutenção dos valores sociais e religiosos, e o compartilhamento de memórias, todos essenciais à manutenção do sentimento de pertencimento a ela. Na concepção de Gil Filho,

\begin{abstract}
O desenvolvimento da identidade religiosa está condicionado a uma determinada temporalidade e espacialidade e perpassa 0 reconhecimento institucional da religião. Já a ideia de pertença permite um reconhecimento não necessariamente institucional da opção religiosa. A identidade religiosa refere-se a uma imagem institucional necessária e demonstra a materialidade da religião e a representação pela qual o indivíduo e o grupo se identificam.

Todavia, ao destacarmos a identidade religiosa, também estamos diante de uma construção que remete à materialidade histórica, à memória coletiva, à espacialidade da própria revelação religiosa processada em determinada cultura. (GIL FILHO, 2008, p.83)
\end{abstract}

Desse modo, o emprego da memória na construção da identidade religiosa buscará nas representações e no espaço elementos que conectem as memórias individuais às memórias do grupo. Dentre eles, a paisagem pode fornecer a base para que as memórias se construam e perpetuem-se. Para Claval, "o sentido de identidade de muitas coletividades sociais está ligado às paisagens da lembrança e da memória" (CLAVAL, 2002, p.22).

As paisagens da memória, portanto, constroem-se a partir das experiências, vivências e valores compartilhados pelas pessoas, o que abarca os processos que envolvem tanto o indivíduo, como também a coletividade. $O$ espaço religioso é um dos espaços que proporcionam tais compartilhamentos, visto que nele os fiéis freqüentadores compartilham experiências e memórias e atribuem sentidos e significados a elas, o que contribui para a construção da 
identidade do grupo de religiosos e da religião, e também para a construção da ideia de mundo, pois os fatos e momentos compartilhados no espaço religioso somam-se às demais experiências pessoais do cotidiano.

As experiências com os elementos do espaço e com os grupos de convívio proporcionam o contato com o passado, e também a construção de identidades e a apropriação, construção e organização do espaço (TORRES, 2009), que se dão a partir do espaço de ação de cada indivíduo. O ser religioso, por sua vez, não tem seu espaço de ação restrito ao espaço do templo, e isso faz do seu cotidiano um amálgama de espaços que contém certa espacialidade do sagrado, uma vez que os valores religiosos estão também no indivíduo, construídos a partir de suas experiências. Lowenthal (1982), ao discorrer sobre a contribuição da experiência na composição da ideia de mundo afirma que os lugares em que frequentamos, visitamos ou percorremos, até mesmo os que lemos e vemos pelas mídias, e os domínios da imaginação, contribuem para as nossas imagens de natureza e do homem. Assim, para este autor, todos os tipos de experiências, desde as mais estreitamente ligadas com o nosso mundo diário até aquelas que parecem remotamente distanciadas, vêm juntos compor o nosso quadro individual da realidade (LOWENTHAL, 1982, p.141). As identidades associam-se ao espaço, pois se baseiam nas lembranças divididas, nos lugares percorridos, nos monumentos que retratam os grandes momentos do passado, nos símbolos gravados nas pedras das esculturas ou nas inscrições (CLAVAL, 1997, p.107).

É por meio das experiências pessoais que o mundo passa a revelar-se para cada indivíduo. No ser religioso, o contato com o sagrado pode definir grande parte do seu espaço de ação, pois a partir dele o indivíduo encontra ou ressalta suas convicções, que terão reflexo em suas atitudes fora do templo, no seu cotidiano.

A experiência corporal apresenta-se como base de toda sensação e percepção, e, consequentemente, toda imaginação e memória simbólicas. Assim, é no contato com o espaço que o indivíduo percebe uma paisagem e ressignifica-a a cada novo contato. Para Cassirer, a percepção decorre do entendimento e compreensão acerca de algo experienciado pelos sentidos, e 
transforma-se em um ato do pensamento puro, em virtude da ação objetiva nele contida (CASSIRER, 2011, p.216). Ao recorrer ao pensamento de Galileu acerca da percepção, Cassirer considera que tudo o que costumamos atribuir ao corpo em relação a um objeto que pensemos estar associado, como suas qualidades sensoriais, odores, sabores e cores, são simplesmente "palavras com as quais designamos não a natureza do objeto em si, mas apenas sua atuação sobre nós, sobre nosso organismo sensível (CASSIRER, 2011, p.38). Ao citar Galileu, torna-se evidente que Cassirer considera que a linguagem está constantemente presente no mundo humano e, nesse sentido, entende-se que mesmo nas mais simples relações estabelecidas entre os seres humanos e os objetos dispostos no espaço, há uma relação simbólica mediada por formas simbólicas, o que distancia o homem do universo dos fatos à medida que o aproxima do universo simbólico, no qual estão as representações e o espaço abstrato concebido. Diante disso, pode-se afirmar que as experiências corporais definem a construção da percepção, que estão diretamente relacionadas às memórias, e que se vinculam às experiências compartilhadas entre as pessoas de um mesmo grupo de convívio social. As experiências vividas e compartilhadas pelas pessoas incluem as mediadas pelos meios de comunicação, pois fazem-se cada vez mais presentes no cotidiano das pessoas, integrando o campo das experiências de segunda mão. Atualmente, há um considerável número de canais de televisão e de rádios com programas religiosos, pelos quais se pode acessar tanto uma mensagem religiosa, quanto apreciar uma música religiosa, o que, em ambos os casos, mostra como as distintas denominações religiosas tem buscado através desses meios a propagação de seus preceitos, objetivando atingir seus seguidores e os possíveis novos fiéis por meio da onipresença do discurso proporcionado pelos meios de comunicação de massa. Ao fazerem uso desses meios, as religiões contribuem ainda mais na construção e reafirmação da visão de mundo do homem religioso.

As experiências adquiridas ou de segunda mão fazem com que incrementemos ainda mais a percepção presente: concebemos as coisas não só como se havíamos visto, senão também como se as houvéssemos ouvido ou tivéssemos lido sobre elas 
antes. [...] A percepção retrospectiva nos permite compreender as paisagens do passado já que não podemos compreender as de um presente incoerente; as imagens recordadas mais compreensíveis de ontem dominam e obscurecem as percepções caleidoscópicas de hoje ${ }^{4}$. (LOWENTHAL, 1998, p.78)

O contato com as histórias de vida de outras pessoas do mesmo convívio social, o compartilhamento de fatos e fenômenos ocorridos na coletividade, são experiências que fazem do espaço e do tempo elementos essenciais à construção da identidade. Do mesmo modo, essas experiências resultam em imagens para cada indivíduo, que, segundo Cassirer (2001), são produtos da capacidade empírica da imaginação produtiva.

[...] o esquema dos conceitos sensíveis (como das figuras no espaço) é um produto e, por assim dizer, um monograma da imaginação pura a priori, através da qual e de acordo com a qual, tão somente, se tornam possíveis as imagens que, entretanto, sempre devem ser ligadas ao conceito por intermédio do esquema que indicam, e com o qual elas não são totalmente congruentes. (CASSIRER, 2001, p.211)

A percepção e a memória integram e participam do complexo das relações sociais e espaciais. São elementos que se constroem no indivíduo, mas influenciam e sofrem influências da coletividade e das formas espaço e tempo. Segundo Cassirer,

A crítica do conhecimento mostra que a simples sensação na qual está pressuposta apenas uma qualidade sensível, mas nenhuma forma de ordenação, não é, de maneira nenhuma, um "fato" da experiência imediata, constituindo, tão-somente, o resultado de uma abstração. A matéria da sensação nunca está dada pura em si e "anteriormente" a toda e qualquer conformação; ao contrário, já a partir do momento de sua primeira percepção, ela se insere em uma relação com as formas espaço e tempo. (CASSIRER, 1994, p.205)

Toda sensação, percepção e memória humana se dão na relação com

\footnotetext{
${ }^{4}$ Tradução livre da versão espanhola. No original: Las experiencias adquiridas o de segunda mano hacen que incrementemos aún más la percepción presente: concebimos las cosas no sólo como si las hubiéramos visto, sino también como si las hubiésemos oído o hubiésemos leído sobre ellas antes. [...] La percepción retrospectiva nos permite comprender los paisajes del pasado ya que no podemos comprender los de un presente incoherente; las imágenes recordadas más comprensibles del ayer dominan y oscurecen las percepciones caleidoscópicas del hoy.
} 
o espaço e com o tempo. Da mesma forma as identidades estão atreladas ao espaço e ao tempo, e constroem-se sobre essa base perpetuando-se sobre ela. Nesse sentido, pensar geograficamente a religião significa pensá-la em sua estreita relação com o espaço, não apenas pela materialidade dos templos ou eventos religiosos, mas, sobretudo, pela espacialização do fenômeno religioso, que se dá por meio do espaço de ação do ser religioso. O espaço de ação do ser religioso coincide com a espacialização do fenômeno religioso, uma vez que "o espaço no qual o fiel realiza suas atividades é marcado pela forma como ele busca explicar sua vida" (SILVA; GIL FILHO, 2009, p.90), o que se dá carregado de significados adquiridos por e a partir da experiência com o sagrado e com a religião. Por sua vez, a espacialização do fenômeno religioso manifesta-se na paisagem, seja aquela estritamente religiosa do interior dos templos ou a de fora deles, o que contribui para a criação de imagens e a evocação de memórias simbólicas e de paisagens da memória.

\section{CONSIDERAÇÕES FINAIS}

As paisagens da memória, frutos das experiências e vivências, e do compartilhamento destas e dos valores sociais e culturais, são fundamentais à manutenção da identidade e da cultura de um grupo. Estudá-las, portanto, exige o entrecruzamento dos elementos que compõem a paisagem, sensível e objetiva, com aqueles percebidos pelos indivíduos e ressignificados pelo grupo, recorrentes em suas memórias.

Os espaços religiosos apresentam-se como locais de compartilhamentos das percepções e das memórias, individuais e coletivas. É nele que os religiosos mantêm suas experiências com o sagrado, e por meio do discurso religioso atribuem significados às diferentes esferas da vida. Assim, a identidade religiosa constrói-se, e indica o espaço de ação do ser religioso, dentro e fora do espaço religioso. Dessa forma, tem-se a manifestação da espacialidade do sagrado, que não se limita ao espaço do templo sagrado, mas extrapola-o, e manifesta-se na paisagem por meio das mais diferentes formas sensíveis.

Diante disso, o estudo da paisagem deve transcender as suas formas 
visíveis e materiais. Apoiar-se nas percepções e significados atribuídos pelos indivíduos que integram-na e vivenciam-na, bem como nas memórias individuais e coletivas, podem aproximar ainda mais o pesquisador do fenômeno religioso e da espacialidade do sagrado.

\section{REFERÊNCIAS BIBLIOGRÁFICAS}

ALMEIDA, M. G. de. Em busca do poético do sertão. In: ALMEIDA, M. G. de, RATTS, A. (orgs.). GEOGRAFIA: leituras culturais. Goiânia: Editora Alternativa, 2003.

ANDREOTTI, G. Per una architettura del paesaggio. Trento: ArtimediaTrentini, 2008.

. O senso ético e estético da paisagem. RA'E GA (Depto. Geografia UFPR), v. 24, p. 05-17, 2012. Disponível em: < www.geografia.ufpr.br/raega/> Acesso em: 15/03/2012.

BERGSON, H. Matéria e memória: ensaio sobre a relação do corpo com o espírito. São Paulo: Martins Fontes, 2006.

BOSI, E. Memória e sociedade: lembranças de velhos. São Paulo: Companhia das Letras, 1994.

CANDAU, J. Memória e identidade. São Paulo: Contexto, 2011.

CASSIRER, E. Ensaio sobre o homem: introdução a uma filosofia da cultura humana. São Paulo: Martins Fontes, 1994.

A filosofia das formas simbólicas: primeira parte: a linguagem. São Paulo: Martins Fontes, 2001.

A filosofia das formas simbólicas: terceira parte: fenomenologia do conhecimento. São Paulo: Martins Fontes - selo Martins, 2011.

CLAVAL, P. As abordagens da Geografia Cultural. In: CASTRO, I. E.; GOMES, P. C. da C.; CORRÊA, R. L. (orgs.). Explorações geográficas: percursos no fim do século. Rio de Janeiro: Bertrand Brasil, 1997.

"A volta do cultural" na Geografia. Mercator - Revista de Geografia da UFC, ano 01, $n^{\circ}$ 01, 2002. (p. 19 - 27). Disponível em: < http://www.mercator.ufc.br/> Acesso em: 08/10/2007.

COSGROVE, D. A Geografia está em toda parte: cultura e simbolismo nas paisagens humanas. In: CORRÊA, R. L.; ROSENDAHL, Z. (orgs.). Paisagem, tempo e cultura. Rio de Janeiro: EdUERJ, 2004.

GIL FILHO, S. F. Espaço sagrado: estudos em geografia da religião. Curitiba: Ibpex, 2008.

HALBWACHS, M. A memória coletiva. São Paulo: Centauro, 2006. 
LOWENTHAL, D. Geografia, experiência e imaginação: em direção a uma epistemologia geográfica. In: CHRISTOFOLETTI, A. (org.). Perspectivas da Geografia. São Paulo: Difusão Editorial, 1982.

El pasado es um país extraño. Madrid: Ediciones Akal, 1998.

SILVA, A. S.; GIL FILHO, S. F. Geografia da Religião a partir das formas simbólicas em Ernst Cassirer: um estudo da Igreja Internacional da Graça de Deus no Brasil. REVER (PUC-SP), v. 1, p. 73-91, 2009.

TORRES, M. A. A paisagem sonora da llha dos Valadares: percepção e memória na construção do espaço. Dissertação de Mestrado em Geografia, UFPR, 2009. 